\title{
Detection of fin, pap, sfa and afa Adhesin-Encoding Operons in Escherichia collistrains Isolated from Urinary Tract Infections
}

\author{
Mahsa Yazdi (PhD) \\ Department of Biology, Faculty of \\ Sciences, University of Isfahan, \\ Isfahan, Iran \\ Majid Bouzari (PhD) \\ Department of Biology, Faculty of \\ Sciences, University of Isfahan, \\ Isfahan, Iran \\ Ezzat Allah Ghaemi (PhD) \\ Laboratory Sciences Research Center, \\ Golestan University of Medical \\ Sciences, Gorgan, Iran \\ Corresponding authors: Majid \\ Bouzari \\ Email: mahsayazdi92@gmail.com \\ Tel: +989133130546 \\ Address: Department of Biology, \\ Faculty of Sciences, University of \\ Isfahan, Hezar Jereeb Street, 81746- \\ 73441, Isfahan, Iran
}

Received : 29 Aug 2017

Revised: 03 Oct 2017

Accepted: 10 Oct 2017

\begin{abstract}
Background and objectives: Urinary tract infections (UTIs) are one of the most common infectious diseases caused by bacteria. The primary etiologic agent of UTIs is Escherichia coli. Uropathogenic E.coli (IPEC) strains have a number of specific virulence factors, which can worsen UTIs. This study was performed to detect fim, pap, sfa and afa genes among E.coli strains isolated from UTIs.

Methods: A total of $100 \mathrm{E}$. coli isolates from patients with UTI was collected between June and December 2015 from Mosavi and Sayyad Shirazi hospitals in Gorgan, Iran. All bacterial isolates were identified via standard biochemical testing and Gram straining. Presence of the genes was assessed by polymerase chain reaction.

Results: The frequency of the fim, pap, sfa and afa genes was 100\%, 79\%, $69 \%$ and $8 \%$, respectively. All isolates contained at least one virulence gene. Prevalence of multiple adhesion genes was $6 \%$ for all genes and $65 \%$ for three genes (fim, pap and sfa) together. In addition, the frequency of the fim gene was significantly higher than that of the other genes $(\mathrm{P}<0.0001)$.

Conclusion: The results of this study indicate the high prevalence of virulence factors that can enhance pathogenicity of $E$. coli. Therefore, these factors could be used as diagnostic markers or vaccine targets.

Keywords: Virulence factors, Urinary tract infection, Uropathogenic Escherichia coli.
\end{abstract}




\section{INTRODUCTION}

Urinary tract infections (UTIs) are inflammatory diseases caused by various pathogens, which alter the correct functioning of the urinary system (1). Escherichia coli is the major cause of UTI and the predominant facultative member of the normal human intestinal flora. The bacterium accounts for more than $80 \%$ of all UTI incidents (2). UTI comprises a range of disorders including cystitis and pyelonephritis, which are characterized by presence of microorganisms such as $E$. coli in the urinary tract $(3,4)$. Only a few $E$. coli strains have the potential to cause UTIs, which are classified as uropathogenic $E$. coli (UPEC) strains (5). UPECs express a multitude of virulence factors such as pili or fimbriae, which break the inertia of the mucosal barrier (6). The ability of these bacteria to adhere to host epithelial cells is considered as a prerequisite for the establishment of infection (7). Pyelonephritisassociated pili or $\mathrm{P}$ fimbriae (pap), type 1 fimbriae, afimbrial adhesin I ( $a f a \mathrm{I})$, hemolysin (hly), cytotoxic necrotizing factor 1 ( cnf 1), aerobactin (aer) and S fimbriae adhesion ( $s f a$ ) are the most important virulence genes in UPEC strains, which are associated with severe UTI $(8,9)$. These virulence factors help the microorganism colonize host surfaces, avoid and/or subvert host defense mechanisms, damage and/or invade host cells and tissues and incite a noxious inflammatory response, thereby leading to a clinical disease (10). UPECs generally possess type 1 and $P$ fimbriae (11). The adhesive subunit of type 1 fimbriae, FimH, is a major determinant, which has high tropism for urinary tract receptors; thus, FimH adhesion is important for colonization of $E$. coli in different niches (1). E. coli $\mathrm{P}$ fimbriae are mannose-resistant hemagglutinins predominant at the cell surface, which are associated with colonization of upper urinary tract and binding to vascular endothelium of the kidney, causing pyelonephritis. The $\mathrm{S}$ fimbriae is a mannoseresistant adhesin encoded by the $s f a$ operon that recognizes $\alpha$-sialyl- $\beta$-2, 3 -galactose receptors in humans. Presence of $\mathrm{S}$ fimbriae is correlated with pathogenicity of $E$. coli in human meningitis and septicemia $(12,13)$. Pathogenic E. coli strains associated with intestinal and extra intestinal infections in humans and animals are reported to express operons of the afa family (14). The afimbrial adhesin is a mannose-resistant, P-independent, $\mathrm{X}$-binding adhesin, encoded by the afa-1 operon that mediates the specific binding to uroepithelial cells and human erythrocyte receptors. The afa operon shows a high degree of heterogeneity among UPEC strains with certain subtypes being predominantly present in pyelonephritis as well as in other UTIs (15). The aim of this study was to detect the virulence genes of E.coli strains isolated from UTIs in Gorgan, Iran.

\section{MATERIAL AND METHODS}

A total of 100 E. coli strains from patients with UTI were collected between June and December 2015 from Mosavi and Sayyad Shirazi hospitals in Gorgan, Iran. The bacterial isolates were identified by Gram staining and biochemical tests, such as catalase, oxidase, indole production, citrate utilization, triple iron sugar, and methyl red-Voges Proskauer as described previously (16). The bacteria were maintained in brain heart infusion broth (Merck, Germany) with glycerol and stored at $-70{ }^{\circ} \mathrm{C}$ for further studies.

Bacterial strains were sub-cultured overnight in brain heart infusion broth and genomic DNA was extracted from typical E. coli colonies using the phenol chloroform extraction method. To extract the DNA from E. coli strains, $1 \mathrm{ml}$ cell suspension was centrifuged and the pellet was resuspended in lysis buffer (Sinnagen, Iran) containing proteinase $\mathrm{K}$ and SDS. After incubating the mixture at $65{ }^{\circ} \mathrm{C}$ for $60 \mathrm{~min}$, phenol: chloroform: isoamyl alcohol (25:24:1) (Merck, Germany) was added and the suspension was shaken and centrifuged at $12000 \mathrm{~g}$ at $22^{\circ} \mathrm{C}$ for $10 \mathrm{~min}$. The supernatant was transferred to a new tube and then mixed with phenolchloroform. The mixture was centrifuged at $9000 \mathrm{~g}$ for $10 \mathrm{~min}$ and the supernatant containing DNA was precipitated with $95 \%$ ethanol and centrifuged as described above. The pellet was washed twice with $70 \%$ cold ethanol $\left(-20{ }^{\circ} \mathrm{C}\right)$. Finally, the precipitate containing DNA was air-dried and dissolved in $50 \mu 1$ of deionized distilled water and was stored at $-20{ }^{\circ} \mathrm{C}$ as a template DNA stock (17). Specific primers were used to detect some virulence factors (fim, pap, sfa, and $a f a$ ) in $E$. coli isolates from patients with UTI. Primers for the adhesin genes were first established individually using a template DNA from 
appropriate positive control strains obtained from the Department of Microbiology of the Golestan University of Medical Sciences. Table 1 shows the primers used for the detection of UPECs' virulence genes. Thermocycling conditions for the polymerase chain reaction process (PCR) are shown in table 2. Amplified DNA products were analyzed by standard submarine gel electrophoresis using $10 \mu \mathrm{L}$ of the final reaction mixture on a $1.5 \%$ agarose gel in TBE buffer. Amplified DNA fragments of specific sizes were visualized by UV fluorescence with SYBR Green I dye (Sinaclone, Iran). A 50 bp ladder (Sinaclone, Iran) was used for determining the molecular size of the PCR products (7). Data were analyzed using GraphPad Prism 6.1 software (GraphPad Software Inc., USA). The Fisher's exact test was used for statistical analysis and P-values less than 0.05 were considered statistically significant.

\section{RESULTS}

Figure 1 shows the results of gel electrophoresis for the detection of the adhesin genes (fim, pap, saf and afa). The most common virulence genes in the isolates were the fim gene (100\%) followed by the pap gene (79\%), the sfa gene $(69 \%)$ and the afa gene $(8 \%)$. The frequency of the fim gene was significantly higher than that of the other genes $(\mathrm{P}<0.0001)$.

All isolates harbored the adhesin genes either singly or in combination. Six isolates (6\%) were positive for all genes and 65 isolates (65\%) were positive for the fim, pap and $s f a$ genes (Table 3).

Table 1-The specific primers used for amplification of fimbriae genes in $E$. coli strains isolated from UTI

\begin{tabular}{|c|c|c|c|}
\hline Gene & Sequence (5' to 3') & Size, bp & Reference \\
\hline fim & $\begin{array}{l}\text { GCTGTGATGTTTCTGCTCGT } \\
\text { AAAACGAGGCGGTATTGGTG }\end{array}$ & 167 & (18) \\
\hline sfa & $\begin{array}{l}\text { CTCCGGAGAACTGGGTGAT } \\
\text { CGGAGGAGTAATTACAAACCTGGCA }\end{array}$ & 410 & (19) \\
\hline afa & $\begin{array}{l}\text { GCT GGG CAG CAA ACT GAT AAC TCT C } \\
\text { CAT CAA GCT GTT TGT TCG TCC GCC G }\end{array}$ & 750 & (12) \\
\hline pap & $\begin{array}{l}\text { GAC GGC TGT ACT GCA GGG TGT GGC G } \\
\text { ATA TCC TTT CTG CAG GGA TGC AAT A }\end{array}$ & 328 & (20) \\
\hline
\end{tabular}

Table 2- PCR thermocycling conditions for detection of the virulence (fimbriae) genes in UPEC strains

\begin{tabular}{|c|c|c|}
\hline Gene & PCR program & PCR reaction mixture $(25 \mu \mathrm{l})$ \\
\hline fim & 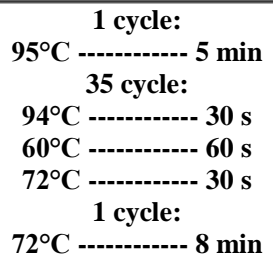 & $\begin{array}{c}2.5 \mu \mathrm{l} \text { PCR buffer 10X } \\
2 \mathrm{mM} \text { MgCl2 } \\
\text { 0.2 mM dNTP } \\
\text { 10 Pmol of each primers F \& R } \\
1.25 \text { U Taq DNA polymerase } \\
3 \mu \mathrm{I} \text { DNA template }\end{array}$ \\
\hline sfa & 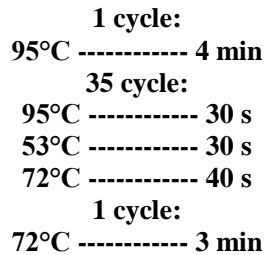 & $\begin{array}{c}2.5 \mu \mathrm{l} \text { PCR buffer 10X } \\
2 \mathrm{mM} \text { MgCl2 } \\
\text { 0.4 mM dNTP } \\
\text { 10 Pmol of each primers F \& R } \\
1.25 \text { U Taq DNA polymerase } \\
3 \mu \mathrm{I} \text { DNA template }\end{array}$ \\
\hline afa & 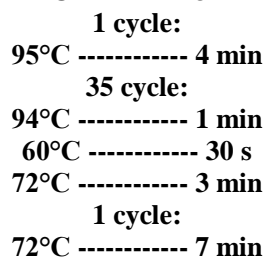 & $\begin{array}{c}2.5 \mu \mathrm{l} \text { PCR buffer 10X } \\
2.3 \mathrm{mM} \text { MgCl2 } \\
\text { 0.2 mM dNTP } \\
\text { 20 Pmol of each primers F \& R } \\
1.25 \text { U Taq DNA polymerase } \\
3 \mu \mathrm{I} \text { DNA template }\end{array}$ \\
\hline pap & 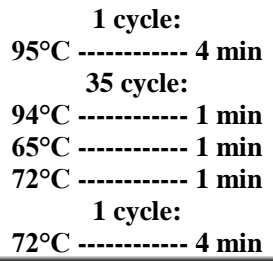 & $\begin{array}{c}2.5 \mu \mathrm{l} \text { PCR buffer 10X } \\
1.5 \mathrm{mM} \text { MgCl2 } \\
\text { 0.2 mM dNTP } \\
\text { 10 Pmol of each primers F \& R } \\
1.25 \text { U Taq DNA polymerase } \\
2 \mu \mathrm{DNA} \text { template }\end{array}$ \\
\hline
\end{tabular}


Table 3- Frequency of the virulence genes alone or in combination in UPEC strains isolated from UTIs

\begin{tabular}{cc}
\hline Virulence genes (alone or in combination) & Number of positive strains \\
\hline fim & 100 \\
pap & 79 \\
sfa & 69 \\
afa & 8 \\
fim, pap & 79 \\
fim, sfa & 69 \\
fim, afa & 8 \\
pap, sfa & 65 \\
pap, afa & 6 \\
Sfa,afa & 6 \\
pap, fim, sfa & 65 \\
pap, fim, sfa, afa & 6 \\
\hline
\end{tabular}

Figure 1- Results of gel electrophoresis for the detection of virulence genes in E. coli strains isolated from UTIs. Column M: 50 bp DNA ladder; column 1: amplified pap gene (328 bp); column 2: amplified afa gene (750 bp); column 3: amplified sfa gene (410 bp); column 4: amplified fim gene (167 bp); column 5: negative control.

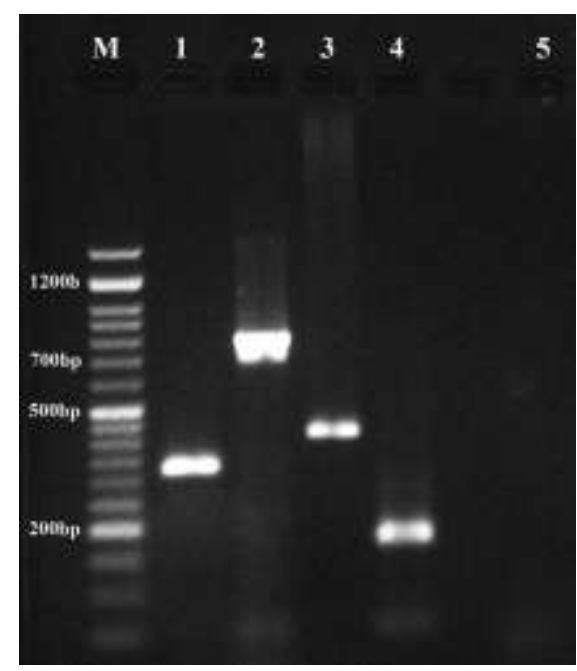

\section{DISCUSSION}

E. coli is the most common cause of UTI in both ambulatory and hospitalized patients (7). Severity of the infection depends on the virulence of the responsible strains and susceptibility of the host, particularly if there is a concomitant urological disease. A better knowledge of the bacterial virulence characteristics assists physicians in diagnosis and treatment of infections. This study was performed to evaluate the frequency of adhesin-encoding operons in E. coli strains isolated from UTIs in Gorgan, northeast of Iran. Several virulence determinants contribute to the pathogenicity of $E$. coli in UTI $(7,21)$, and PCR allows detection of the genes encoding these determinants $(13,22)$. The adhesive systems are the most common virulence factors in UPECs. They play an important role in colonization and invasion of the bladder epithelial cells by UPECs (5, 18). PCR is a highly specific, informative and a powerful genotypic assay used for the detection of virulence factors. In this study, fim was the predominant gene (100\%) in the $E$. coli isolates compared to the pap, sfa and afa genes. These results are consistent with results of previous studies $(5,19,20)$. Garofalo et al. studied 18 UPEC isolates collected from females and found that the fim gene was present in all isolates (23). In another study, Watts et al. reported presence of the fim $H$ gene in $98 \%$ of E. coli strains isolated from patients with UTI (24). Rahdar et al. evaluated the distribution of virulence genes among UPEC strains and reported that $95 \%$ of the isolates contained the fim gene (7). These findings may indicate the crucial role of this gene in the virulence of $E$. coli strains causing UTI. In this study, the frequency of the pap and $s f a$ virulence genes was $79 \%$ and $69 \%$, respectively. Saki et al. also indicated the high frequency of these virulence genes in patients with UTI in Iran (5). Some studies reported the high frequency of combined pap and $s f a$ genes 
$(24,25)$. The high number of samples containing the pap and sfa genes together could be due to the localization of these genes on the same pathogenicity island in UPEC strains $(15,26)$.

Similar to our results, previous studies on the frequency of the $s f a$ and $a f a$ gene combination among UPEC isolates reported that this gene combination is either absent or less documented $(15,19)$. In the present study, $65 \%$ of the strains carried the fim, pap and sfa genes together. This is in agreement with findings of a recent study by Shetty et al., which stated that presence of strains with multiple adhesin genes might further increase the risk for development of UTI, particularly in women (15).

\section{CONCLUSION}

We speculate that the high prevalence of the fim, pap, and $s f a$ operons may be

\section{REFERENCES}

1. Hojati Z, Zamanzad B, Hashemzadeh M, Molaie R, Gholipour A. The FimH gene in uropathogenic Escherichia coli strains isolated from patients with urinary tract infection. Jundishapur J Microbiol. 2015; 8 (2): e17520. doi: 10.5812/jjm.17520.

2. Tiba MR, Yano T, Leite DdS. Genotypic characterization of virulence factors in Escherichia coli strains from patients with cystitis. Rev Inst Med Trop Sao Paulo. 2008; 50(5): 255-60.

3. Karimian A, Momtaz H, Madani M. Detection of uropathogenic Escherichia coli virulence factors in patients with urinary tract infections in Iran. Afr $\mathbf{J}$ Microbiol Res. 2012; 6(39): 6811-6. DOI: 10.5897/AJMR12.1462.

4. Kulkarni R, Dhakal BK, Slechta ES, Kurtz Z, Mulvey MA, Thanassi DG. Roles of putative type II secretion and type IV pilus systems in the virulence of uropathogenic Escherichia coli. PLoS One. 2009;4(3):e4752. doi: 10.1371/journal.pone.0004752.

5. Saki A, Mirzaee M. Frequency of Fimbrial Virulence Genes (fim, pap, sfa) in Escherichia Coli Isolated from the Patients with Urinary Tract Infections. J Shahid Sadoughi Univ Med Sci. 2017; 24(11): 913-923.

6. Bien J, Sokolova O, Bozko P. Role of uropathogenic Escherichia coli virulence factors in development of urinary tract infection and kidney damage. Int J Nephrol. 2012; 2012:681473.

7. Rahdar M, Rashki A, Miri HR, Ghalehnoo MR. Detection of pap, sfa, afa, foc, and fim adhesin-encoding operons in uropathogenic Escherichia coli isolates collected from patients with urinary tract infection. Jundishapur J Microbiol. 2015; 8(8): e22647. doi: $10.5812 /$ jjm. 22647.

8. Donnenberg MS, Welch RA. Virulence determinants of uropathogenic Escherichia coli: Urinary tract infections: molecular pathogenesis and clinical management. ASM Press, Washington, DC; 1996. responsible for UTIs in the study area. High prevalence of virulence factors can enhance the capacity of UPEC strains for colonization of the urogenital tract, resulting in increased bacterial attachment to target cells and increased pathogenicity. Thus, these genes could be targeted for vaccine production for prevention of $E$. coli infections. Further studies are required to identify virulence factors of $E$. coli strains causing UTIs and to determine the pathophysiology of these infections.

\section{ACKNOWLEDGEMENTS}

This study was financially supported by a joint grant from the University of Isfahan and Golestan University of Medical Sciences, Iran [35/219525].

\section{CONFLICT OF INTEREST}

The authors declare that there is no conflict of interest.

9. Johnson JR. Virulence factors in Escherichia coli urinary tract infection. Clin Microbiol Rev. 1991; 4(1): $80-128$.

10. Tajbakhsh E, Ahmadi P, Abedpour-Dehkordi E, Arbab-Soleimani N, Khamesipour F. Biofilm formation, antimicrobial susceptibility, serogroups and virulence genes of uropathogenic E. coli isolated from clinical samples in Iran. Antimicrob Resist Infect Control. 2016; 5(1):11.

11. Snyder JA, Lloyd AL, Lockatell CV, Johnson DE, Mobley HL. Role of phase variation of type 1 fimbriae in a uropathogenic Escherichia coli cystitis isolate during urinary tract infection. Infect Immun. 2006; 74(2): 138793.

12. Knöbl T, Gomes T, Vieira M, Bottino J, Ferreira A. Detection of pap, sfa and fim adhesin-encoding operons in avian pathogenic Escherichia coli. Int J Appl Res Vet Med. 2004;2:135-141.

13. Ott M, Hoschützky H, Jann K, Van Die I, Hacker J. Gene clusters for $S$ fimbrial adhesin (sfa) and $\mathrm{FlC}$ fimbriae (foc) of Escherichia coli: comparative aspects of structure and function. J Bacteriol. 1988;170(9):398390.

14. Le Bouguenec C, Archambaud M, Labigne A. Rapid and specific detection of the pap, afa, and sfa adhesinencoding operons in uropathogenic Escherichia coli strains by polymerase chain reaction. J Clin Microbiol. 1992;30(5):1189-93.

15. Shetty A, Kumar S, Shekar M, Shetty A, Karunasagar I. Prevalence of adhesive genes among uropathogenic Escherichia coli strains isolated from patients with urinary tract infection in Mangalore. Indian J Med Microbiol. 2014;32(2):175.

16. Dash SK, Chakraborty SP, Mandal D, Roy S. Isolation and characterization of multi drug resistant uropathogenic Escherichia coli from urine sample of urinary tract infected patients. Int J Life Sci Pharma Res. 2012;2:25-39. 
17. Bagheri H, Ghaemi A, Aslani M, Mozafari N, Livani $\mathrm{S}$, Dadgar $\mathrm{T}$. The Prevalence of Enteroaggregative Escherichia coli in cases of Diarrhea in Gorgan, IRAN. Med Lab J. 2008;2(1):70.

18. Pusz P, Bok E, Mazurek J, Stosik M, Baldy-Chudzik $\mathrm{K}$. Type 1 fimbriae in commensal Escherichia coli derived from healthy humans. Acta Biochim Pol. 2014;61(2):389-92.

19. Blanco M, Blanco J, Alonso M, Mora A, Balsalobre C, Munoa F, et al. Detection of pap, sfa and afa adhesinencoding operons in uropathogenic Escherichia coli strains: relationship with expression of adhesins and production of toxins. Res Microbiol. 1997;148(9):74555.

20. Nazemi A, Naderi M, Jafarpour M, Mirinargesi M, Sharifi SH. The Detection of Fimbrial Pathogenic Genes in E.coli Strains Isolated from Patients with Urinary Tract Infection. Med Lab J. 2010; 4(2):31-7.

21. Antão E-M, Wieler LH, Ewers C. Adhesive threads of extraintestinal pathogenic Escherichia coli. Gut Pathog. 2009;1(1):22.
22. Farshad S, Emamghorashi F. The prevalence ofvirulence genes of $E$. coli strains isolated from children with urinary tract infection. Saudi J Kidney Dis Transpl. 2009;20(4):613.

23. Garofalo CK, Hooton TM, Martin SM, Stamm WE, Palermo JJ, Gordon JI, et al. Escherichia coli from urine of female patients with urinary tract infections is competent for intracellular bacterial community formation. Infect Immun. 2007;75(1):52-60.

24. Watts RE, Hancock V, Ong C-LY, Vejborg RM, Mabbett AN, Totsika M, et al. Escherichia coli isolates causing asymptomatic bacteriuria in catheterized and noncatheterized individuals possess similar virulence properties. J Clin Microbiol. 2010;48(7):2449-58.

25. Silveira WDd, Benetti F, Lancellotti M, Ferreira A, Solferini VN, Brocchi M. Biological and genetic characteristics of uropathogenic Escherichia coli strains. Rev Inst Med Trop Sao Paulo. 2001;43(6):303-10.

26. Dobrindt U, Blum-Oehler G, Hartsch T, Gottschalk G, Ron EZ, Fünfstück R, et al. S-Fimbria-Encoding Determinant sfa I Is Located on Pathogenicity Island III536 of UropathogenicEscherichia coli Strain 536. Infect Immun. 2001;69(7):4248-56. 